\title{
História, historiografia e saber histórico escolar: a educação para as relações étnico-raciais e o saber histórico na literatura didática ${ }^{1}$
}

\author{
Mauro Cezar Coelho* \\ Wilma de Nazaré Baía Coelho ${ }^{* *}$
}

\section{Resumo}

\begin{abstract}
O presente trabalho analisará a abordagem dada pela literatura didática à educação para as relações etnico-raciais. Para tanto, a análise incide nos conteúdos apontados pelas diretrizes estabelecidas, pela legislação em vigor, para o trato das questões étnico-raciais. Nesse sentido, os autores consideram uma coleção didática destinada à Educação de Jovens e Adultos (EJA), de modo a perceber os modos pelos quais os autores da coleção acionam o saber historiográfico e o saber escolar na promoção da educação para as relações étnico-raciais. O objetivo é perceber em que medida o saber axiológico, demandado pela legislação, é encaminhado por meio do recurso ao saber histórico, tanto o historiográfico quanto o escolar. A partir da análise da coleção, destacamos que a noção de que a História é um instrumento pedagógico por meio do qual se ensina com exemplos edificantes, que personificam a luta por um mundo melhor, entendido como livre de conflitos é o que consubstancia, como se vê, o saber histórico escolar aqui considerado.
\end{abstract}

Palavras-chave: História. Historiografia e saber histórico escolar. Relações étnico-raciais. EJA.

Os estudos relacionados à História ensinada acumulam-se há algum tempo. $\mathrm{O}$ percurso traçado por esses vêm desenhando, desde onde percebemos, não apenas um novo campo da pesquisa histórica, mas uma área específica, a qual analisa um saber que, ainda que relacionado ao saber historiográfico, não se confunde com este. A História ensinada não se constitui pela simplificação do saber acadêmico, objetivando a sua apropriação em situação escolar. Antes, esse concretiza-se pela transposição didática do saber acadêmico (CHEVALLARD, 2005), historiográfico,

Recebido: 27/05/2014 - Aprovado: 04/07/2014

http://dx.doi.org/10.5335/rep.v21i2.4306

Doutor em História Social pela Universidade de São Paulo. Professor Adjunto da Universidade Federal do Pará. E-mail: mauroccoelho@yahoo.com.br.

** Doutora em Educação pela Universidade Federal do Rio Grande do Norte. Professora Associada da Universidade Federal do Pará. E-mail: wilmacoelho@yahoo.com.br. 
em saber acessível a indivíduos em situação escolar. A história ensinada é circunscrita por outros objetivos, outras bases epistemológicas, outras situações de produção e, sobretudo, outros interlocutores.

A distinção sugerida aqui não constitui o escopo do presente artigo. Situá-la, todavia, é fundamental para a reflexão que oferecemos. Iniciemos, então, pelos objetivos do saber histórico escolar. No Brasil, a disciplina de História esteve, desde o início, relacionada à formação e à valorização da nação. Por longo período, esteve vinculada ao fomento do patriotismo, por meio do conhecimento e do estabelecimento de vínculos com os símbolos pátrios (HORTA, 1994). Nas últimas cinco décadas, esse sentido pedagógico vem sendo substituído pela preocupação com a formação do cidadão (fosse o conformado pela lógica da segurança nacional [sic], fosse o cidadão crítico, após o fim da Ditadura Civil/Militar) (COELHO, 2009, p. 263-280).

O saber histórico escolar esteve, então, frequentemente vinculado a objetivos que subordinaram a compreensão do passado aos fins projetados pelo momento político. Mais que os objetivos, no entanto, é a situação de produção que demarca, de modo definitivo, a distinção entre os saberes aqui destacados. Tanto quanto a compreensão do passado, é a necessidade de engendrar cognição o que circunscreve o saber histórico escolar. Este aciona, para tanto, não somente as matrizes teóricas recorrentes entre os historiadores, mas, principalmente, teorias da aprendizagem e da didática. O saber histórico conforma-se, ainda, de duas formas que, mesmo complementares, não se confundem: a aula e o texto didático. Finalmente, o saber histórico escolar está voltado para um público específico, a comunidade escolar, diante da qual se concretiza. Diferentemente do saber historiográfico, criticado e dimensionado pelos pares (CERTEAU, 1988, p. 20-24), esse assume todo o seu potencial nas situações de aprendizagem, por meio do seu uso, qual é feito por professores, alunos e demais agentes escolares.

Por isso, defendemos que o estudo da História ensinada compreende o campo de estudos da História, mas não se confunde com a pesquisa do passado e a sua problematização. Antes, esse ocupa-se com os usos do passado em situação de aprendizagem. Nesse processo, também recorre-se a um arcabouço teórico específico, voltado para a compreensão das situações da aprendizagem ou da trajetória da disciplina. Isso frequentemente é encarado como uma dimensão menor dos estudos históricos, o que pode ser percebido tanto pelo número de pesquisas relacionadas ao ensino de História desenvolvidas em programas de pós-graduação em História, quanto pelo lugar da formação docente nos cursos de graduação em História, mesmo e principalmente os de licenciatura (FERREIRA, 2011, p. 141-162). Sobretudo, o estudo da História ensinada tem como escopo uma intervenção no curso das ações. Em alguma medida, esse pressupõe a possibilidade de alteração no ensino oferta- 
do, seja por meio do aprimoramento da prática docente, da melhoria do material didático, do aperfeiçoamento dos procedimentos didáticos, enfim, da qualificação e do refinamento do processo de ensino-aprendizagem.

Essa breve reflexão introdutória pareceu-nos necessária, a fim de melhor situar o objetivo deste artigo. Por meio desse, pretendemos analisar a abordagem dada pela Literatura Didática à educação para as relações étnico-raciais. Por conseguinte, a análise incidirá nos conteúdos apontados pelas diretrizes estabelecidas pela legislação em vigor para o trato das questões étnico-raciais. Nesse sentido, consideramos uma coleção didática, destinada à Educação de Jovens e Adultos, de modo a perceber os modos pelos quais os autores acionam o saber historiográfico e o saber axiológico na promoção da educação para as relações étnico-raciais. $O$ objetivo é perceber em que medida o saber escolar, demandado pela legislação, é dimensionado na relação necessária que mantém com os objetivos formulados para a disciplina no ensino fundamental e com a produção historiográfica.

\section{Educação para as relações étnico-raciais e a Educação de Jovens e Adultos}

Não nos ocuparemos da trajetória da educação de jovens e adultos no Brasil. Há inúmeros trabalhos que se ocupam dessa questão com propriedade (DI PIERRO, 2010, p. 939-959; HADDAD; DI PIERRO, 2000, p. 29-40; RUMMERT; VENTURA, 2007, p. 29-45). A nossa intenção nesta seção do artigo é refletir a importância da educação para as relações étnico-raciais nessa modalidade de ensino. $\mathrm{E}$, a questão é articular os propósitos dessa última aos encaminhamentos dados à educação para as relações étnico-raciais.

Desde a implantação da legislação promulgada em 2003, um volume significativo de trabalhos tem se ocupado com efetivação das leis n. 10.639/03 e 11.645/08 (COELHO; COELHO, 2012, p. 137-155; COELHO; COELHO, 2013, p. 92-107; MULLER; COELHO, 2013, p. 29-54). Parte daquele volume volta sua atenção para os modos pelos quais as temáticas abordadas pela legislação são implementadas na educação básica, operadas e apropriadas por alunos, professores, técnicos e gestores. Ocupados com a oferta educacional para indivíduos em idade escolar, tais trabalhos problematizam as estratégias recorrentes para o enfrentamento da política educacional, considerando, ainda que de forma subjacente, a adequação das iniciativas ao primeiro ou ao segundo ciclo do ensino fundamental e do ensino médio.

Tais estudos não assumem, evidentemente, ser a escola a única fonte de acesso à memória, por crianças e adolescentes. Todavia, compreendem que é por meio dessa que os alunos da educação básica têm acesso ao saber formal relacionado ao passado conformado em conteúdo de uma disciplina. Em muitos casos, é por meio desta disciplina que os alunos estabelecem os primeiros contatos com a trajetória 
histórica brasileira e ocidental, apreendendo narrativas (RÜSEN, 2001) a respeito do passado brasileiro, especialmente da conformação da nacionalidade.

Dentre as diversas especificidades da Educação de Jovens e Adultos, destacamos, justamente, o fato de que para muitos dos alunos desta modalidade a escola e os seus assuntos são antigos conhecidos. Mesmo se considerarmos os adultos que vivenciam o primeiro contato com a escola, a experiência acumulada na vida (como cidadãos, trabalhadores, consumidores de cultura, agentes, enfim, do tempo em que vivem) proporciona-lhes uma visão e um posicionamento do passado. E nisso reside toda a diferença. A consideração da proposta curricular para essa modalidade de ensino deixa isso claro.

A Proposta Curricular para a Educação de Jovens e Adultos: segundo segmento do ensino fundamental $-5^{\mathrm{a}}$ a $8^{\mathrm{a}}$ série, doravante Proposta, é um documento importante pela abrangência das questões que incorpora: um diagnóstico da oferta da Educação de Jovens e Adultos; os pressupostos da educação que se pretende ofertar; e a base curricular projetada para a modalidade. Tais questões reunidas permitem que se sopese as especificidades dessa modalidade de ensino, de modo a perceber o lugar que o ensino de História ocupa e alcança na formação pretendida para os milhares de brasileiros e, também, como a educação para as relações étnico-raciais articula-se nessa modalidade.

Em relação ao diagnóstico, a Proposta Curricular para a Educação de Jovens e Adultos aponta algumas das características de ensino. Em primeiro lugar, a faixa etária dos alunos. O levantamento considerado pela proposta baseava-se em dados do ano 2000, os quais apontavam que cerca de $70 \%$ da clientela tinha mais de 18 $\operatorname{anos}^{2}$ e por volta de $40 \%$ alcançara oito anos de estudo (BRASIL, 2002d, p. 22). Em segundo lugar, as condições de permanência na escola. A repetência era uma constante entre os alunos da modalidade - ainda que maior e determinante no primeiro ciclo do ensino fundamental, era acentuada na passagem da sétima para a oitava série, no segundo ciclo (BRASIL, 2002f, p. 25). Em terceiro lugar, o acesso à educação na história familiar. Na região Norte, que nos interessa particularmente, cerca de $70 \%$ dos pais dos alunos cursaram até a antiga $3^{\text {a }}$ série, visto que um índice significativo (por volta de 30\%) sequer frequentou a escola. Em quarto lugar, o percurso educacional dos alunos: $44 \%$ cursara até a $4^{\mathrm{a}}$ série (BRASIL, 2002g, p. 34).

Além das características dos alunos, a proposta procedeu ao diagnóstico do ensino de História. Os dados coletados apontaram que parte dos professores adotava uma abordagem linear, tanto no trato da História do Brasil quanto no que se referia à História do mundo, fazendo-a da seguinte forma: " 5 ” série, História do Brasil, desde a vinda dos portugueses até a chegada da família real; $6^{\underline{a}}$ série, História do Brasil, do movimento da Independência até os dias atuais; $7^{a}$ série, Antiguidade e Idade Média; 8aㅗ série, Idade Moderna e contemporânea". O diagnóstico feito pela 
proposta considera que o encaminhamento dado pelos docentes objetivava uma reflexão dos problemas do mundo contemporâneo e o fomento de uma educação promotora do exercício da cidadania (BRASIL, 2002a, p. 61).

No que se refere aos pressupostos, a partir dos quais a oferta da Educação de Jovens e Adultos é pensada, a Proposta enfatiza que as funções dessa modalidade de educação são reparar, equalizar e qualificar. Desde o início, portanto, a proposta formulada pela instância pública qualifica a Educação de Jovens e Adultos como uma política de inclusão social, por meio do saneamento das lacunas na formação e, sobretudo, das injustiças que concorreram para a sua exclusão da escola, de forma a proporcionar aos interessados, as mesmas condições atingidas por aqueles que cumpriram a educação básica no período ideal. Ademais, essa formação é vista como uma estratégia de qualificação dos jovens e adultos, vinculando a modalidade à potencialização das oportunidades dos egressos no mercado de trabalho e na vida cidadã (BRASIL, 2002b, p. 87).

A Proposta elege as reflexões de Paulo Freire como a matriz teórica que a fundamenta. Esta destaca das concepções de Freire, especialmente, o caráter interativo da aprendizagem e a importância da experiência de vida do aluno nesse processo, além, é claro, de sua opção por uma educação emancipadora (BRASIL, 2002c, p. 97-99). Diante disso, a Proposta não encaminha um rol de disciplinas e conteúdos a partir dos quais a aprendizagem será construída, mas um conjunto de competências que se quer ver desenvolvidas pelo aluno jovem e adulto. Transcrevemo-las a seguir:

Compreender a cidadania como participação social e política, assim como exercício de direitos e deveres políticos, civis e sociais, adotando, no dia-a-dia, atitudes de solidariedade, cooperação e repúdio às injustiças, respeitando o outro e exigindo para si o mesmo respeito. Posicionar-se de maneira crítica, responsável e construtiva nas diferentes situações sociais, utilizando o diálogo como forma de mediar conflitos e de tomar decisões coletivas.

Conhecer características fundamentais do Brasil nas dimensões sociais, materiais e culturais como meio para construir progressivamente a noção de identidade nacional e pessoal e o sentimento de pertinência ao país.

Conhecer e valorizar a pluralidade do patrimônio sociocultural brasileiro, bem como aspectos socioculturais de outros povos e nações, posicionando-se contra qualquer discriminação baseada em diferenças culturais, de classe social, de crenças, de sexo, de etnia ou de outras características individuais e sociais.

Perceber-se integrante, dependente e agente transformador do ambiente, identificando seus elementos e as interações entre eles, contribuindo ativamente para a melhoria do meio ambiente.

Desenvolver o conhecimento ajustado de si mesmo e o sentimento de confiança em sua capacidade afetiva, física, cognitiva, ética, estética, de inter-relação pessoal e de inserção social, para agir com perseverança na busca de conhecimento e no exercício da cidadania. Conhecer o próprio corpo e dele cuidar, valorizando e adotando hábitos saudáveis como um dos aspectos básicos da qualidade de vida e agindo com responsabilidade em relação a sua vida e à saúde coletiva. 
Utilizar diferente linguagens - verbal musica, matemática, gráfica, plástica e corporal como meio de produzir, expressar e comunicar suas ideias, interpretar e usufruir as produções culturais, em contextos públicos e privados, atendendo a diferentes intenções e situações de comunicação.

Saber utilizar diferentes fontes de informação e recursos tecnológicos para adquirir e construir conhecimentos.

Questionar a realidade, formulando problemas e tratando de resolvê-los, utilizando para isso o pensamento lógico, a criatividade, a intuição, a capacidade de análise crítica, selecionando procedimentos e verificando sua adequação (BRASIL, 2002h, p. 115-119).

A transcrição do longo rol de competências é fundamental para que possamos dimensionar as possibilidades que essas abrem para o trabalho com a memória e, da mesma forma, os nexos estabelecidos com o ensino de História. Senão vejamos. As dez competências elegem a formação para a cidadania e para a crítica como as bases estruturantes do processo de ensino e aprendizagem da modalidade. Tal formação é entendida de forma ampla, compreendendo a ampliação da participação social e política, o repúdio às injustiças, o desenvolvimento do respeito mútuo, a recusa às discriminações, a assunção de responsabilidades e o domínio de diversas linguagens.

A modalidade, então, acompanha uma orientação das políticas educacionais e da reflexão a respeito da formação básica, desde há algumas décadas, relacionando-a a formação do cidadão crítico. Esta, compreende, conforme encaminha a Proposta, a tomada de consciência dos direitos e deveres, o repúdio às injustiças e a assunção de uma atitude propositiva diante do contexto imediato, no qual o aluno está inserido. Importa, nesse sentido, considerar como a mesma Proposta relaciona tais competências no âmbito do ensino de História, de modo a garantir os objetivos últimos da modalidade - reparar, equalizar e qualificar.

A seção voltada para a História elege os seguintes objetivos para a disciplina:

Estabelecer relações entre a vida individual e social, identificando relações sociais em seu próprio grupo de convívio, na localidade, na região e no país, relacionando-as com outras manifestações, em outros tempos e espaços.

Situar acontecimentos e localizá-los em uma multiplicidade de tempos.

Reconhecer que o conhecimento histórico é parte do conhecimento interdisciplinar.

Compreender que as histórias individuais são partes integrantes de histórias coletivas.

Questionar sua realidade, identificando problemas e possíveis soluções, conhecendo formas político-institucionais e organizações da sociedade civil que permitam atuar sobre a realidade. Dominar procedimentos de pesquisa escolar e de produção de texto, aprendendo a observar e colher informações de diferentes paisagens e registros escritos, iconográficos e materiais. Valorizar o patrimônio sociocultural e respeitar a diversidade social.

Valorizar o direito de cidadania dos indivíduos, dos grupos e povos, como condição para fortalecer a democracia, respeitando-se as diferenças e lutando contra as desigualdades (BRASIL, 2002i, p. 112-118). 
Tais objetivos estão em estreita relação com os objetivos da modalidade. $\mathrm{O}$ ensino de História é apropriadamente relacionado ao desenvolvimento da consciência histórica (RÜSEN, 2009, p. 163-209; 2001), contribuindo para a situação do indivíduo no tempo e para a compreensão da historicidade das conformações sociais. Ele também é vinculado ao domínio de competências relacionadas à formação da aprendizagem, por meio da instrumentalização do aluno para o trato e o domínio com o saber sistematizado, como observação, identificação e anotação, por meio do trato com diferentes registros. A formação do cidadão e do sujeito crítico não é esquecida - o trato com a memória e a diversidade social, por meio do cuidado com a preservação do patrimônio histórico e do respeito à diferença, é entendida como uma competência vinculada, de modo particular, à disciplina.

A Proposta sugere que os objetivos supracitados sejam buscados por meio de um enfoque temático, em substituição à abordagem linear, costumeiramente utilizada pelos professores. Os eixos temáticos são percebidos, inicialmente, não somente como uma alternativa à visão quadripartite (CHESNEAUX, 1995), mas como uma alternativa crítica à compreensão de que a trajetória brasileira constitui-se como apêndice da história europeia. Além disso, esses eixos permitiriam, de modo mais consequente, o estabelecimento de vínculos entre o presente e o passado e a percepção da participação de todos nos processos históricos considerados. Para tanto, o documento encaminha quatro sugestões de eixos temáticos: Migrações, cultura e identidades e Trabalho e relações sociais, para turmas iniciais, e Relações de poder e conflitos sociais e Cidadania e cultura contemporânea para turmas em continuidade (BRASIL, 2002j, p. 121-126; p. 128-132).

Os encaminhamentos sugeridos pela Proposta fazem eco a questões há muito recorrentes nas discussões relacionadas ao ensino de História. Abordá-las, de forma a apresentar um quadro dos debates identificando o lugar e os rumos da disciplina ultrapassa os limites deste artigo. Diante disso, apontaremos a seguir os nexos que o documento engendra com a educação para as relações étnico-raciais. Importa ressaltar que o documento é anterior à promulgação das leis que introduzem as temáticas da cultura afro-brasileira, da história indígena e da história da África na educação básica, não obstante os encaminhamentos sugeridos permitem a reflexão dos nexos que a Proposta estabelece para a consecução da legislação que nos interessa.

A educação para as relações étnico-raciais constitui parte das políticas de ação afirmativa que, também buscam reparar, equalizar e qualificar. Mais que incluir conteúdos, as leis número 10.639/03 e 11.645/08 demandam o redimensionamento da memória histórica. Ao incorporar agentes e processos desprezados ou subdimensionados nas narrativas que dizem respeito à conformação do Brasil e 
da nacionalidade, elas pretendem redefinir a perspectiva a partir da qual nossa formação é percebida: em primeiro lugar, promovem a crítica à visão eurocêntrica e quadripartite; em segundo lugar, potencializam a identificação com o passado, na medida em que privilegiam agentes e processos internos; em terceiro lugar, fomentam o exercício da cidadania, ao considerar como agentes consequentes dos processos históricos grupos tradicionalmente excluídos, em função da atribuição de juízos que os assumem como incapazes.

\section{0 livro didático e os parâmetros curriculares}

Selecionamos a coleção Tempo de Aprender: Educação de Jovens e Adultos - $6^{\underline{0}}$ ao $9^{\circ}$ ano do ensino fundamental. ${ }^{3}$ Trata-se de série de quatro volumes multidisciplinares. A coleção foi aprovada pelo Programa Nacional do Livro Didático para o triênio 2011, 2012 e 2013. ${ }^{4}$ O edital PNLD/EJA - 2011 estabeleceu um corpo mínimo de componentes, deixando a critério dos autores e editores o tipo de abordagem que receberiam, reconhecendo duas dessas como as mais usuais - a linear e a temática. ${ }^{5}$ Esta última é percebida como especialmente eficaz, em função das possibilidades de articulação de conteúdos entorno de um tema gerador. Interessa-nos, no entanto, o que o edital estabelece em relação à educação para as relações étnico-raciais na História.

Há referência expressa à necessidade de as obras contemplarem a cultura afro-brasileira, a história indígena e a história da África, relacionando-as ao combate, à discriminação e ao racismo. ${ }^{6}$ Em relação à História, o edital recomenda que as obras didáticas promovam o raciocínio histórico e a distinção entre os processos vividos e as formas pelas quais estes são apreendidos pela escrita histórica. Para tanto, o edital recomenda que as obras recorram ao saber historiográfico, destacando o caráter social daquela produção, despertem os alunos para a condição histórica dos contextos sociais e utilizem ilustrações variadas, as quais permitam o uso pedagógico da imagem. ${ }^{7}$

Conheçamos, então, a coleção selecionada. Cada volume apresenta sete partes: Língua Portuguesa, Matemática, História, Geografia, Ciências Naturais, Língua Estrangeira Moderna - Inglês e Artes. Cada parte, portanto, está voltada ao enfrentamento de uma disciplina e é desenvolvida por dois ou três intelectuais responsáveis. Todos os volumes seguem a mesma orientação gráfica e didática. Em cada um dos volumes, as partes são divididas em duas unidades e cada unidade em dois ou três capítulos. Os organizadores da coleção elegeram temáticas que organizam o conteúdo em todas as disciplinas, de modo que cada volume estabelece dois temas abordados para cada uma delas. 
A coleção elege oito temas a serem tratados ao longo do segundo ciclo do ensino fundamental: Identidade e Cidadania e Leitura no 6⿳⺈ ano; Meio Ambiente e Saúde e Qualidade de Vida no $7^{\circ}$ ano; Cidadania e Cultura e Cultura da Paz no $8^{\circ}$ ano; Trabalho e Consumo e Globalização e Novas Tecnologias no $9^{\circ}$ ano. A abordagem também segue um padrão único para todas as disciplinas. Os capítulos são compostos por nove seções: "Pra começo de conversa", "Desvendando o tema", "Sua vez...", "Aprofundando o tema", "Trabalhando com o texto", "Revelando o que aprendeu", "Ampliando o tema", "Momento lúdico" e "E eu com isso". Algumas disciplinas são contempladas, ainda, com seções próprias: "Revelando a própria história", para a disciplina de História; "Um olhar para a língua", para a disciplina de Língua Portuguesa e "Um olhar para a matemática", para a disciplina de Matemática.

Cada seção tem função específica. "Pra começo de conversa", "Desvendando o tema", "Aprofundando o tema", "Revelando a própria história" e "Ampliando o tema" são seções voltadas para a abordagem da temática, estabelecendo o saber a ser construído em situação de aprendizagem. A ordem das seções dá conta do grau de complexidade adotado no trato da temática da unidade. Assim, "Pra começo de conversa" tem a função de estimular o leitor para as questões a serem tratadas. "Desvendando o tema" busca definir a temática, relacionando-a a aspectos da vida dos alunos/leitores - função específica, aliás, da seção "E eu com isso".

No que tange ao saber histórico, as seções obedecem aos princípios gerais estabelecidos para a coleção. As seções "Pra começo de conversa" e "Desvendando o tema" cumprem, a um só tempo, a função de introduzir o assunto, relacionando-o à vida do aluno, como forma de estimulá-lo. O saber historiográfico, propriamente dito, é introduzido a partir da seção "Aprofundando o tema", o qual é aprofundado nas seções "Revelando a própria história" e "Ampliando o tema". As seções "Sua vez...", "Trabalhando com o texto", "Revelando o que aprendeu" e "Momento lúdico" buscam promover momentos de avaliação e pretendem, também, estabelecer nexos entre os temas abordados e a experiência dos alunos/leitores.

Como se vê, a coleção opera com determinada perspectiva acerca do saber escolar. Em um primeiro momento, fica claro que esse saber não se restringe ao saber especializado. Ao eleger temáticas abordadas pelas diversas disciplinas, os editores não apenas manifestam uma preocupação multidisciplinar, mas estabelecem um percurso didático que expressa sua compreensão do processo de ensino e aprendizagem. Em relação a isso, vejamos como os editores definem o objetivo da coleção: a promoção de um aprendizado significativo, resultado da reunião dos "conteúdos tradicionais com conteúdos fundamentais que o ajudarão a compreender o mundo em que vive e atuar nele de forma crítica e inovadora". 8 
O saber escolar operado na coleção, como se pode perceber, não se restringe aos "conteúdos tradicionais", mas engloba, também e principalmente, os "conteúdos fundamentais", essenciais para a compreensão do mundo, com o objetivo de desenvolver "atitudes e competências fundamentais para o exercício da cidadania". O saber escolar é entendido, portanto, como algo mais que os "conteúdos tradicionais", o qual os ultrapassa, estabelecendo um saber específico, o qual não se limita ao domínio de determinada área do conhecimento, mas que se concretiza no trato com cada uma delas.

Nesse sentido, a coleção vai ao encontro das discussões em curso, as quais problematizam o saber escolar, distinguindo-o do saber acadêmico. Essa característica da coleção concorreu, neste artigo, para a sua seleção como objeto de discussão. Ao compreender o saber escolar como algo mais que o "conteúdo" de cada disciplina, entendido como o saber especializado em dada área do conhecimento, a coleção permite que reflitamos o "saber histórico escolar" (VADEMARIN, 1998, p. 73-84; MONTEIRO, 2001, p. 57-67; CARDOSO, 2007, p. 209-226) positivamente, sopesando sua relação com o saber acadêmico.

Por fim, a coleção estabelece objetivos e adota perspectiva em tudo afeita ao que determina e recomenda a Proposta. A promoção do aprendizado significativo adequa-se ao propósito definido para a modalidade de garantir o aumento da participação social dos jovens e adultos, por meio de um aprendizado que promova a consciência de si e do mundo.

\section{História, historiografia e saber histórico escolar: as relações étnico-raciais}

Considerar o saber histórico escolar, promovido pela coleção, implica sopesar o sentido atribuído ao saber histórico.

O estudo do passado das diferentes sociedades humanas permite o resgate e a compreensão das realizações humanas, de suas causas e consequências, fornecendo-nos parâmetros para o entendimento do nosso presente e permitindo deduções sobre como será o futuro.

História é a ciência que estuda o passado, as mudanças nas sociedades ao longo do tempo, a sequência de acontecimentos, de fatos reais, estágios que marcaram a evolução da humanidade, de uma personagem, de um aspecto da atividade humana em um certo lugar e em um certo período (BRASIL, 2009f, p. 177).

O estudo da História é vinculado, então, a uma pedagogia do exemplo, a partir da qual se pode entender não somente os significados do passado, mas como agir no futuro (KOSELLECK, 1985, p. 21-38). A História é entendida, por meio dessa perspectiva, como uma ciência do passado, a partir da qual se aprende a viver o presente e, principalmente, a transformá-lo. A disciplina assim pensada, em que 
pese à recusa de uma perspectiva tida como superada, na qual os grandes homens perfilam-se soberanos, em favor de outra, em que a História é percebida como construção de todos, não se distancia de um aporte no qual a narrativa dos fatos do passado permanece como estratégia de ensino. Pois, essa serve ao propósito último de ensinar a intervir no presente por meio de uma crítica moral das ações. Isto fica claro na medida em que a coleção inicia o trato com a trajetória histórica brasileira. Ao abordar a questão dos direitos, a coleção evoca uma noção alheia ao pensamento histórico, pois não considera a mudança e não considera a historicidade das relações sociais. "Ao longo da história brasileira, os direitos foram exclusivos de uma minoria privilegiada e não eram reconhecidos nas leis e nos costumes para a maioria da população" (BRASIL, 2009g, p. 216).

A afirmação merece atenção, pois permite vislumbrar como aquele sentido pedagógico concretiza-se na História ensinada na coleção. A trajetória histórica brasileira é percebida como um processo único, sem distinções demarcadas pelo tempo e pelo espaço. Assim, explicam-se a compreensão de que categorias como Direito, Minoria, Privilégio, Legislação e Costume não são dimensionadas pelo tempo, mas tem um sentido absoluto. Há que se considerar, por conseguinte, o tratamento dado à categoria cidadania, nos três capítulos que a abordam, no primeiro volume da coleção.

O capítulo "Cidadania e leitura" é iniciado com uma breve consideração a respeito dos direitos das pessoas com deficiência visual. A seguir, a seção "Ser cidadão no Brasil - a lei e a prática" discorre sobre o significado da cidadania na Constituição de 1988, situando o descompasso entre o que diz a legislação e a vida cotidiana, em que "os direitos de seus cidadãos não são respeitados" (BRASIL, 2009a, p. 215). Essa consideração serve de introdução ao excerto supracitado. Esse, por sua vez, anuncia o tratamento com a abordagem da cidadania no Império: "O imperador estava no topo da hierarquia havendo abaixo dele os privilegiados da terra - grandes proprietários, cuja maior preocupação era a manutenção do poder político, o controle sobre a terra e a escravidão" (BRASIL, 2009b, p. 216).

A sociedade imperial, como se vê, perde toda a complexidade evidenciada pela produção historiográfica e é apresentada de modo simplificado e dicotômico, a partir de seus dois polos - os senhores e os escravos. A seguir, a coleção sugere que os leitores reflitam o tema e o relacionem as suas vidas (BRASIL, 2009c, p. 218-224).

O capítulo seguinte, "Cidadania - uma construção histórica", apresenta um relato dos primeiros códigos legislativos, a partir do mito da Torre de Babel, do Código de Hamurabi (a partir do qual se faz uma digressão da importância da escrita, relacionando-a com o exercício do poder, por meio da referência ao Egito 
Antigo), do Direito Romano e da Democracia Grega. Esta última é abordada a partir da seguinte constatação: "Na história humana, desde que surgiu a 'democracia', o problema localiza-se nos seguintes questionamentos: Quem é considerado cidadão? Quais são os direitos do cidadão?” (BRASIL, 2009d, p. 232) A partir daí a democracia grega é apresentada graficamente, na forma de uma pirâmide que tem os hilotas na base e os cidadãos no topo.

Como se pode perceber, a coleção atribui um importante sentido para os conteúdos relativos à Antiguidade. Esses servem à discussão da Cidadania e Direitos e da importância da escrita como um instrumento de exercício do poder. No entanto, a coleção não encaminha uma perspectiva histórica. A máxima atribuída à trajetória brasileira é estendida à "história da humanidade" à medida que a cidadania é percebida como um privilégio de poucos e não como construção social e, portanto, transitória. A necessidade pedagógica de instituir o saber histórico como um aprendizado por meio do exemplo, e do qual se aprende o certo e o errado, com vistas à conscientização e a transformação do futuro é o que informa essa postura.

O último dos três capítulos que trata da questão "Cidadania e imprensa" é elucidativo nesse aspecto, no qual a trajetória da imprensa no Brasil é abordada por meio do destaque dispensado ao lugar que os jornais impressos ocuparam nas disputas políticas, especialmente a partir da instauração da República, e a relação dos jornais com os grupos políticos em confronto. Novamente, a coleção elege um meio produtivo para dar conta da trajetória política brasileira, desde a Independência e o papel desempenhado pela imprensa na vida política. Sobre isso, os alunos jovens e adultos detém alguma experiência, pois, de uma forma ou de outra, mantém contato com a imprensa escrita, falada ou televisionada, participam da vida política e podem dimensionar a importância dos suportes jornalísticos no passado, a partir do papel que esses desempenham no presente.

Todavia, o enfoque adotado não considera fatores importantes, tanto no que diz respeito à trajetória histórica, quanto no que concerne à complexidade das relações políticas e do fato jornalístico. Os jornais são percebidos a partir da mesma matriz dicotômica já anotada, de modo que se dividem entre a imprensa operária e a imprensa burguesa. Os leitores não são considerados, de forma que o fato jornalístico é conformado apenas a partir da intenção do jornal. As leituras possíveis formuladas pelos leitores, os movimentos sociais que indicam as ações e as demandas da sociedade e a própria trajetória da imprensa brasileira - sua diversidade e as circunstâncias de sua formação, especialmente no século XX - não são abordados, como se a trajetória política brasileira no século XX fosse, exclusivamente, uma ação das elites. 
O sentido atribuído ao saber histórico emerge da coleção como vinculado a duas necessidades: a primeira, ensinar por meio do exemplo; a segunda, a denúncia das injustiças e das desigualdades. Diante delas, é pouco acionado o saber historiográfico relativo à vida política republicana no século XX, em relação a qual e aos demais assuntos de que tratam as partes da coleção voltadas para o conteúdo histórico, o saber historiográfico é acionado por meio de excertos de textos, cuja função é reiterar o sentido absoluto pretendido pelo texto didático em questão. A condição de saber construído, própria da historiografia, não é considerada, privilegiando-se a narrativa dos eventos. $\mathrm{O}$ enfoque temático, nesse sentido, não serve à discussão da construção do conhecimento histórico - por meio do tratamento com documentos e com as questões do tempo - ou da crítica à memória. Os nexos sugeridos pelas temáticas não correspondem a nexos sugeridos pela historiografia, mas ao assunto abordado. Vejamos outro exemplo.

A temática da segunda unidade, do segundo livro da coleção, é "Saúde e qualidade de vida". No capítulo três dessa unidade, são arrolados os seguintes processos: o tempo presente, por meio de referências às moradias e a alimentação do Brasil contemporâneo, e o passado histórico, a partir do espaço urbano na Roma Antiga, e os seus problemas sanitários, da Peste Negra, na Idade Média, das primeiras políticas públicas de saneamento urbano, na Idade Moderna, e, finalmente, do Brasil, a partir de referências às cidades coloniais, às epidemias ocorridas durante o Império, e, por último, às primeiras políticas de vacinação, no início da República. Os nexos não são sugeridos pela indicação de vínculos que relacionam a questão sanitária nas cidades antigas, medievais, modernas e brasileiras, mas pela necessidade de exemplificar e de despertar o aluno para o cuidado com a saúde e com o meio ambiente. Os nexos consagrados pelo saber historiográfico, os quais apontam a relação entre políticas sanitárias, saber médico, controle social e expansão dos cuidados com a saúde não são mencionados.

O saber histórico escolar encaminhado pela coleção, então, pouca relação mantém com o saber historiográfico. As obras citadas ou referidas emergem como exemplos das ações humanas e não como expressões da trajetória da própria disciplina, dificultando a distinção entre o passado vivido e o saber construído sobre ele, privilegiando a narrativa em lugar da consideração da História como um saber que, como os outros, é resultado de um processo (KNAUSS, 2005, p. 279-295). Significativo, nesse sentido, é o lugar ocupado pelas temáticas referentes à história da África e à história indígena.

O primeiro volume, destinado ao sexto ano, traz duas unidades, "Identidade" e "Cidadania e leitura". A primeira referência aos índios faz-se na segunda unidade, em meio à consideração dos outros tipos de leitura, além da escrita. 
Em uma sociedade letrada, o acesso ao conhecimento também depende do domínio e da interpretação que se tem da leitura dos sinais impressos. Enquanto nas sociedades indígenas, as informações estão nos formatos, cores e cheiros presentes na floresta e na natureza. Isso significa que o indígena, que sabe ler o que diz a natureza, está mais preparado em seu meio, para exercer o seu direito à vida, obter alimentos e remédios necessários à sua sobrevivência (BRASIL, 2009c, p. 218).

Nessa oportunidade, os indígenas aparecem vinculados à natureza, encaminhando uma percepção daqueles povos que escapa à diversidade de configurações da vida indígena no Brasil de hoje. A segunda referência ocorre no segundo volume, na primeira unidade, a qual discute a temática "Meio ambiente". Nesta, o foco é a agricultura e não os povos indígenas, como pode-se observar pelo excerto a seguir:

Se a história oficial do Brasil teve início com a chegada dos portugueses em 1500, o mesmo não se pode dizer da agricultura em nossas terras. Os primeiros habitantes de nosso país praticavam uma agricultura de subsistência: plantavam, preferencialmente, mandioca para complementar uma alimentação baseada na coleta de frutos e raízes, e caçavam pequenos animais (BRASIL, 2009i, p. 192).

Inicialmente notamos que a coleção opera uma categoria pouco elucidativa, "a história oficial", vinculando-a a chegada dos portugueses. A ausência de discussão no que diz respeito aos significados de "história oficial" permite apropriações diversas, sem relação necessária com as intenções dos autores. Interessa-nos destacar, no entanto, o fato de que os povos indígenas são referidos por meio do qualificativo primeiros habitantes. Mais uma vez, a diversidade de configurações sociais, linguísticas e culturais é encoberta por meio da adoção de uma categoria generalizante.

Os povos indígenas são retomados à narrativa no terceiro volume. Na unidade "Cidadania e cultura", a primeira referência está situada no título da seção "Tribo não é só de indígena”. Voltada para a discussão da diversidade cultural brasileira, a seção pretende despertar o aluno para "as origens de nossa diversidade" (BRASIL, 2009j, p. 180). Na sequência, "Os primeiros habitantes", dá continuidade ao tema, abordando os povos indígenas habitantes do território, quando da chegada dos portugueses. A diversidade indígena, anunciada na seção anterior é assim situada: "Antes da chegada dos europeus, o Brasil era habitado por diversos povos, que foram chamados de índios, com línguas, tradições e religiões diferentes entre si. Em todo o território, talvez houvesse pouco mais de 5 milhões de pessoas" (BRASIL, 2009l, p. 181).

A noção de diversidade cultural é relacionada, então, à variedade de povos. As disputas, diferenças e guerras que demarcavam as relações entre muitos desses povos não são referidas. Por meio desse encaminhamento, a diversidade perde seu caráter de posicionamento político, a partir do qual se reconhece, respeita e valoriza 
a diferença. Mais que isso, o sentido histórico da noção de diversidade e seu vínculo com as lutas sociais vividas desde a segunda metade do século XX é desprezado (PEREIRA; BAHIA, 2011, p. 51-71; GERALDES; ROGGERO, 2011, p. 471-487). A noção de diversidade, assim como os povos indígenas, é colocada fora do contexto histórico.

A seguir, o capítulo aborda as relações existentes entre portugueses e indígenas, situando-as em dois polos: exploração e resistência. Os portugueses guerreavam os indígenas com o objetivo de escravizá-los e os indígenas opunham-se aos portugueses. A narrativa oferece dois exemplos de resistência indígena - a Confederação dos Tamoios e os povos indígenas habitantes do Centro-Oeste, como os Guaicuru - sem problematizá-las, assumindo como absolutos os dois polos apontados.

Mesmo que a ausência de nexos com a historiografia que, há décadas, analisa a complexidade das relações, envolvendo indígenas e a sociedade colonial (MONTEIRO, 1984; CUNHA, 1987; FARAGE, 1991; GRUPIONI, 1992; CUNHA, 1992), chama a atenção o encaminhamento didático dado pela coleção. A simplificação dos processos históricos, evidenciada pela adoção de uma perspectiva dicotômica, a partir da qual os agentes são apresentados de modo estático e unidimensional, é coerente com o saber histórico escolar ofertado, logo, não é tanto a apreensão de competências que permitam a percepção do passado como resultado das ações dos agentes o que esse objetiva, mas a apreensão de determinada perspectiva moral, a partir da qual se pode identificar o certo e o errado.

Essa parece ser a razão pela qual os povos indígenas aparecem de forma tão tímida na coleção. Ainda no capítulo com que nos ocupamos agora, uma única seção, intitulada "Não são preguiçosos, mas diferentes", traça a trajetória dos povos indígenas desde a colonização portuguesa até os dias atuais. A atenção especial não é dispensada a outros agentes, de modo que o parágrafo final deixa clara a forma pela qual a coleção percebe o lugar dos indígenas na trajetória histórica brasileira:

Entre os diversos povos indígenas que ainda habitam nossas terras, alguns estão buscando se integrar ao mercado de compra e venda, e outros estão retomando antigos hábitos e costumes para reencontrar a autoestima perdida. Buscam algo que não encontram na cultura ocidental: as suas integridades física, cultural e espiritual (BRASIL, 2009m, p. 184).

Ao longo de toda a narrativa, é reforçada a ideia segundo a qual os indígenas estão fora da sociedade nacional. Esses não participam da "história oficial", não se adequam à cultura ocidental e vivem em luta pela manutenção de sua integridade. Não se questiona o fato de os povos indígenas viverem em luta permanente pelo reconhecimento, manutenção e ampliação de seus direitos. É o encaminhamento didático que os apresenta sob uma única perspectiva, que minimiza sua participação na conformação da sociedade nacional, que os assume de forma homogênea, deixando de lado suas diferenças, o que problematizamos. 
Tal perspectiva pode ser percebida no trato dado à história da África e da presença africana e negra no Brasil. Não há qualquer seção do conteúdo de História voltado para a compreensão de processos ocorridos no continente africano (exceção feita à referência ao Apartheid, na África do Sul, ao abordar a cultura da não violência, em meio à temática Cultura da $\mathrm{Paz}^{9}$ ). No que tange ao que frequentemente entende-se por cultura afro-brasileira, a abordagem volta-se para o tema da escravidão. Mais uma vez, o aporte busca situar os agentes em dois polos, nesse caso a classe dominante e os escravos (BRASIL, 2009n, p. 190). O texto não se apropria da extensa historiografia da escravidão africana, seja para situar a imensa contribuição africana à economia colonial - além da força de trabalho, como detentores de inúmeros conhecimentos fundamentais para as economias agrícola e mineradora seja para apontar a complexidade das relações que demarcaram a sociedade escravista (SCHWARTZ, 2001). A seção seguinte, "A resistência negra” (BRASIL, 2009o, p. 191), aponta algumas das formas de resistência, reforçando a compreensão de que apenas duas ações eram possíveis - submeter-se ou revoltar-se.

$\mathrm{O}$ modo como as questões indígenas e africanas são tratadas é relacionado à abordagem do preconceito. Na unidade "Cidadania e cultura", há duas seções, "O Estatuto da Igualdade Racial em debate" e "Muitas origens culturais e um só país", voltadas para a discussão do tema. Apesar da referência ao fato de que o racismo é apreendido, as seções não promovem uma abordagem histórica, de modo que esse é percebido somente do ponto de vista moral, como um desvio. Evidencia-se nesta parte do texto, mais uma vez, o princípio didático que orienta a conformação do saber histórico escolar: desenvolver no aluno uma crítica moral das ações, por meio de uma abordagem simplista dos processos históricos, segundo a qual os agentes históricos são apresentados de forma unidimensional. Nesta, a complexidade da vida social é substituída pelo estabelecimento de relações de oposição, por meio das quais o vivido torna-se mais facilmente compreensível. Perspectiva coerente com o sentido do estudo do passado, tal como a coleção o apresenta: "o estudo do passado das diferentes sociedades humanas permite o resgate e a compreensão das realizações humanas, de suas causas e consequências" (BRASIL, 2009p, p. 177).

O saber histórico escolar promovido pela coleção é consoante com os pressupostos e objetivos da Proposta Curricular para a Educação de Jovens e Adultos: segundo segmento do ensino fundamental $-5^{\mathrm{a}}$ a $8^{\mathrm{a}}$ série. Esse saber encaminha uma crítica moral das ações que objetiva, como apontamos acima, o aumento da participação de jovens e adultos na vida política e social do mundo em que vivem, por meio da apreensão de um parâmetro do certo e do errado, em termos de vida social e política. Esse encaminhamento tem o propósito claro de transformação social, com vistas à edificação de um mundo solidário e sem injustiças. 


\section{Considerações finais}

Em outras análises de livros didáticos de História, temos apontado que o saber histórico escolar, operado por tais obras, pauta-se pelo conteúdo axiomático. As análises têm demonstrado que as dimensões psicopedagógicas e axiomáticas, eleitas pela literatura didática, determinam a apropriação do saber historiográfico (COELHO, 2010; COELHO, 2013a, p. 65-82; COELHO; COELHO, 2013b, p. 92107). Este, ainda que concorra para a crítica da memória e para a conformação de uma perspectiva histórica no trato com o passado, está subordinado aos objetivos estabelecidos para o saber histórico escolar, o qual é concebido para o processo de escolarização de crianças, adolescentes e adultos.

O saber histórico escolar, tal como os livros o apresentam, tem como função principal conscientizar o estudante das suas reais condições de existência, as quais somente poderiam ser percebidas por meio da crítica e da reflexão. Conscientizar, conforme o encaminhamento dado, significa compreender o passado a partir de uma visão que tem como valor principal o estabelecimento de uma sociedade sem injustiças. Tal posicionamento relaciona saber histórico escolar à edificação de uma economia moral, a qual determine os valores do justo e do injusto, não de uma perspectiva histórica, mas em relação a um ideal assumido como universal e atemporal.

É significativo, nesse sentido, o lugar do exemplo na coleção didática aqui analisada:

O que podemos considerar eticamente positivo?

Talvez não seja possível afirmar o que é bom ou ruim para todos, mas é possível identificar em algumas pessoas a ética e a moral como práticas vivas, isto é, uma fervorosa negação de um mundo injusto e tão cheio de conflitos.

A História está cheia de exemplos de pessoas que representaram ou representam essas práticas na negação e reformulação de valores que priorizam o individualismo e perseguem grupos ou pessoas simplesmente por pensarem e agirem diferente das classes dominantes (BRASIL, 2009q, p. 246).

A noção de que a História é um instrumento pedagógico e que diante deste ensina-se por meio de exemplos edificantes, que personificam a luta por um mundo melhor, entendido como livre de conflitos é o que consubstancia, como se vê, o saber histórico escolar aqui considerado. Tal noção não está ausente da Proposta Curricular para a Educação de Jovens e Adultos: segundo segmento do ensino fundamental $-5^{\mathrm{a}}$ a $8^{\mathrm{a}}$ série, como já destacamos. Isso aponta para o fato de que a compreensão do significado da História ensinada seja, em linhas gerais, compartilhada por historiadores, instituições públicas de controle e administração da educação e de agentes escolares. Esse é um ponto importante para a crítica e para a reflexão do lugar do ensino de História na educação escolar, especialmente para aqueles que constituem o campo de estudos da História e que almejam a melhoria das condições do ensino - intervindo, positivamente, no objeto que estudam. 


\section{History, historiography and school's historical knowledge: education for ethnic - racial relations and historical knowledge in Educational Literature.}

\section{Abstract}

This paper will examine the approach developed by the Educational Literature for Racial-Ethnic Relations Teaching. In order to do so, the analysis will focus on the contents indicated by the guidelines established by the legislation in force for the treatment of ethnic and racial issues. Thus, the authors will consider a specific didactical collection, aimed at the Youth and Adult Education, in order to understand the ways in which the authors of said collection trigger historiographical and school knowledge in promoting Education for Racial-Ethnic Relations. The goal is to understand to what extent the axiological knowledge, demanded by law, it is forwarded through the use of historical knowledge, both the school and historiographical ones. From the analysis of the collection, we stressed out that the notion that history is a teaching tool through which we teach through edifying examples that embody the struggle for a better world, understood as conflicts free is what constitutes, as it turns out, the historical school knowledge considered here.

Keywords: History. Historiography and school knowledge historic. Ethnic and race relations. EJA.

\section{Notas}

1 Este artigo é resultado parcial da pesquisa As representações sobre o índio e nacionalidade nos livros didáticos consumidos na Região Norte, financiada pelo Conselho Nacional de Desenvolvimento Científico e Tecnológico, Edital Universal 2012.

2 Brasil. Proposta Curricular para a Educação de Jovens e Adultos, 2002d, p. 23.

3 BRASIL, Ministério da Educação. Educação de Jovens e Adultos: $6^{\circ}$ ao $9^{\circ}$ ano do ensino fundamental. 2009e. 4 volumes.

4 BRASIL. MEC. Guia de livros didáticos: PNLD 2011. p. 139.

5 BRASIL. MEC. Edital de Convocação para Inscrição no Processo de Avaliação e Seleção de Obras e Coleções Didáticas para o Programa Nacional do Livro Didático para Educação de Jovens e Adultos - PNLD EJA 2011a. p. 31.

6 BRASIL. MEC. Edital de Convocação para Inscrição no Processo de Avaliação e Seleção de Obras e Coleções Didáticas para o Programa Nacional do Livro Didático para Educação de Jovens e Adultos - PNLD EJA 2011b. p. 33.

7 BRASIL. MEC. Edital de Convocação para Inscrição no Processo de Avaliação e Seleção de Obras e Coleções Didáticas para o Programa Nacional do Livro Didático para Educação de Jovens e Adultos - PNLD EJA 2011. p. 54-55.

8 O excerto em destaque encontra-se no início de cada volume, em seção única, na qual há uma carta para o aluno assinada pelos autores.

9 Neste caso, menos que a África é Nelson Mandela o objeto de interesse do texto didático. 


\section{Referências}

BRASIL, Ministério da Educação. Secretaria de Educação Fundamental. Proposta Curricular para a Educação de Jovens e Adultos: segundo segmento do Ensino Fundamental - 5 a a $8^{\mathbf{a}}$ série. v. I. Brasília: Secretaria de Educação Fundamental, 2002a, p. 61.

Ministério da Educação. Secretaria de Educação Fundamental Proposta Curricular para a Educação de Jovens e Adultos: segundo segmento do Ensino Fundamental: 5ª a $8^{\mathbf{a}}$ série. v. I. Brasília: Secretaria de Educação Fundamental, 2002b, p. 87.

Ministério da Educação. Secretaria de Educação Fundamental Proposta Curricular para a Educação de Jovens e Adultos: segundo segmento do Ensino Fundamental: 5ª a $8^{\mathrm{a}}$ série. v. I. Brasília: Secretaria de Educação Fundamental, 2002c, p. 97-99.

. Ministério da Educação. Secretaria de Educação Fundamental. Proposta Curricular para a Educação de Jovens e Adultos: segundo segmento do Ensino Fundamental: 5ª a $8^{\text {a }}$ série. v. I. Brasília: Secretaria de Educação Fundamental, 2002d, p. 23.

Ministério da Educação. Secretaria de Educação Fundamental. Proposta Curricular para a Educação de Jovens e Adultos: segundo segmento do Ensino Fundamental: $5^{\mathbf{a}}$ a $8^{\mathbf{a}}$ série. v. I. Brasília: Secretaria de Educação Fundamental, 2002e, p. 22.

Ministério da Educação. Secretaria de Educação Fundamental. Proposta Curricular para a Educação de Jovens e Adultos: segundo segmento do Ensino Fundamental: $5^{\mathrm{a}}$ a $8^{\mathrm{a}}$ série. v. I. Brasília: Secretaria de Educação Fundamental, 2002f, p. 25.

. Ministério da Educação. Secretaria de Educação Fundamental Proposta Curricular para a Educação de Jovens e Adultos: segundo segmento do Ensino Fundamental: $5^{\mathbf{a}}$ a $8^{\mathbf{a}}$ série. v. I. Brasília: Secretaria de Educação Fundamental, 2002g, p. 34.

Ministério da Educação. Secretaria de Educação Fundamental Proposta Curricular para a Educação de Jovens e Adultos: segundo segmento do Ensino Fundamental: $5^{\mathrm{a}}$ a $8^{\mathrm{a}}$ série. v. I. Brasília: Secretaria de Educação Fundamental, 2002h, p. 115-119.

Ministério da Educação. Secretaria de Educação Fundamental Proposta Curricular para a Educação de Jovens e Adultos: segundo segmento do Ensino Fundamental: $5^{\mathbf{a}}$ a $8^{\mathrm{a}}$ série. v. I. Brasília: Secretaria de Educação Fundamental, 2002i, p. 112-118.

. Ministério da Educação. Secretaria de Educação Fundamental Proposta Curricular para a Educação de Jovens e Adultos: segundo segmento do Ensino Fundamental: $5^{\mathrm{a}}$ a $8^{\mathrm{a}}$ série. v. I. Brasília: Secretaria de Educação Fundamental, 2002j, p. 121-126; 128-132.

. Ministério da Educação. Edital de Convocação para Inscrição no Processo de Avaliação e Seleção de Obras e Coleções Didáticas para o Programa Nacional do Livro Didático para Educação de Jovens e Adultos - PNLD EJA 2011a. Brasília, 18 de setembro de 2009, p. 54-55. Disponível em: http://www.fnde.gov.br/programas/livro-didatico/livro-didatico-editais/item/3014-editais-anteriores. Acesso em: 23 mar. 2014.

. Ministério da Educação. Edital de convocação para inscrição no processo de avaliação e seleção de obras e coleções didáticas para o Programa Nacional do Livro Didático para Educação de Jovens e Adultos - PNLD EJA 2011a. Brasília, 18 de setembro de 2009, p. 31. Disponível em: http://www.fnde.gov.br/programas/livro-didatico/livro-didatico-editais/item/3014-editais-anteriores. Acesso em: 23 mar. 2014. 
. Ministério da Educação. Edital de convocação para inscrição no processo de avaliação e seleção de obras e coleções didáticas para o Programa Nacional do Livro Didático para Educação de Jovens e Adultos - PNLD EJA 2011b. Brasília, 18 de setembro de 2009, p. 33. Disponível em: http://www.fnde.gov.br/programas/livro-didatico/livro-didatico-editais/item/3014-editais-anteriores. Acesso em: 23 mar. 2014.

. Ministério da Educação. Guia de livros didáticos: PNLD 2011 - EJA. Brasília: MEC; SECAD, 2010, p. 139.

BRASIL, Ministério da Educação. Educação de Jovens e Adultos: $6^{\circ}$ ao $9^{\circ}$ ano do ensino fundamental. São Paulo: IBEP, 2009a. v. I, $6^{\circ}$ ano, p. 215.

Educação de Jovens e Adultos: $6^{\circ}$ ao $9^{\circ}$ ano do ensino fundamental. São Paulo: IBEP, 2009b. v. I, $6^{\circ}$ ano, p. 216.

Educação de Jovens e Adultos: $6^{\circ}$ ao $9^{\circ}$ ano do ensino fundamental. São Paulo: IBEP, 2009c. v. I, $6^{\circ}$ ano, p. 218-224.

Educação de Jovens e Adultos: $6^{\circ}$ ao $9^{\circ}$ ano do ensino fundamental. São Paulo: IBEP, 2009d. v. I, 6⿳⺈ ano, p. 232.

Educação de Jovens e Adultos: $6^{\circ}$ ao $9^{\circ}$ ano do ensino fundamental. São Paulo: IBEP, 2009e. 4 volumes.

Educação de Jovens e Adultos: $6^{\circ}$ ao $9^{\circ}$ ano do ensino fundamental. São Paulo: IBEP, 2009f. v. I, $6^{\circ}$ ano, p. 177.

Educação de Jovens e Adultos: $6^{\circ}$ ao $9^{\circ}$ ano do ensino fundamental. São Paulo: IBEP, 2009 g. v. I, $6^{\circ}$ ano, p. 216.

Educação de Jovens e Adultos: $6^{\circ}$ ao $9^{\circ}$ ano do ensino fundamental. São Paulo: IBEP, 2009h. v. I, $6^{\circ}$ ano, p. 218.

. Educação de Jovens e Adultos: $6^{\circ}$ ao $9^{\circ}$ ano do ensino fundamental. São Paulo: IBEP, 2009i. v. II, $7^{\circ}$ ano, p. 192.

. Educação de Jovens e Adultos: $6^{\circ}$ ao $9^{\circ}$ ano do ensino fundamental. São Paulo: IBEP, 2009 j. v. III, $8^{\circ}$ ano, p. 180.

Educação de Jovens e Adultos: $6^{\circ}$ ao $9^{\circ}$ ano do ensino fundamental. São Paulo: IBEP, 2009l. v. III, $8^{\circ}$ ano, p. 181.

. Educação de Jovens e Adultos: $6^{\circ}$ ao $9^{\circ}$ ano do ensino fundamental. São Paulo: IBEP, 2009m. v. III, 8o ano, p. 184.

. Educação de Jovens e Adultos: $6^{\circ}$ ao $9^{\circ}$ ano do ensino fundamental. São Paulo: IBEP, 2009n. V. III, 8a ano, p. 190.

Educação de Jovens e Adultos: $6^{\circ}$ ao $9^{\circ}$ ano do ensino fundamental. São Paulo: IBEP, 2009o. v. III, 8o ano, p. 191.

. Educação de Jovens e Adultos: $6^{\circ}$ ao $9^{\circ}$ ano do ensino fundamental. São Paulo: IBEP, 2009p. v. I, $6^{\circ}$ ano, p. 177.

Educação de Jovens e Adultos: $6^{\circ}$ ao $9^{\circ}$ ano do ensino fundamental. São Paulo: IBEP, 2009q. v. III, 8o ano, p. 246. 
CARDOSO, Oldimar Pontes. Representações dos professores sobre saber histórico escolar. Cadernos de Pesquisa, São Paulo, v. 37, n. 130, p. 209-226, jan./abr. 2007.

CERTEAU, Michel de. A operação histórica. In: LE GOFF, Jacques; NORA, Pierre. História: novos problemas. Rio de Janeiro: Francisco Alves Editora, 1988. p. 17-48; p. 20-24.

CHESNEAUX, Jean. Devemos fazer tábula rasa do passado? Sobre a História e os historiadores. Edição. São Paulo: Ática, 1995.

CHEVALLARD, Yves. La transposicion didática. Del saber sábio al saber enseñado. Buenos Aires: Aique Grupo Editor, s.d., 2005.

COELHO, Mauro Cezar. As populações indígenas no livro didático ou a construção de um agente histórico ausente. In: COELHO, Wilma de Nazaré Baía; MAGALHÃES, Ana Del Tabor (Orgs.). Educação para a diversidade: olhares sobre a educação para as relações étnico-raciais. Belo Horizonte: Mazza Edições, 2010. p. 97-111.

. A história, o índio e o livro didático: apontamentos para uma reflexão sobre o saber histórico escolar. In: ROCHA, Helenice Aparecida Bastos; REZNIK, Luís; MAGALHÃES, Marcelo de Souza (Orgs.). A história na escola: autores, livros e leituras. Rio de Janeiro: Ed. FGV, 2009. p. 263-280.

. Moral da História: a representação do índio em livros didáticos. In: SILVA, Marcos (Org.). História: que ensino é esse? Campinas-SP: Papirus, 2013a. p. 65-82.

COELHO, Mauro Cezar; COELHO, Wilma de Nazaré Baía. Jogando verde e colhendo maduro: historiografia e saber histórico escolar no ensino de história da África e da cultura Afro-Brasileira. Territórios e Fronteiras (Online). v. 6, p. 92-107, 2013b. Disponível em: <http://www.ppghis. com/territorios\&fronteiras/index.php/v03n02/article/view/247/180>. Acesso em: 6 jun. 2014.

COELHO, Wilma de Nazaré Baía; COELHO, Mauro Cezar. Por linhas tortas a educação para a diversidade e a questão étnico-racial em escolas da região norte: entre virtudes e vícios. Revistas da Associação Brasileira de Pesquisadores (as) Negros (as) - ABPN, v. 4, n. 8, p. 137-155, jul./ out. 2012.

CUNHA, Jorge Luiz da; CARDOSO, Lisliane dos Santos. Ensino de história e formação de professores: narrativas de educadores. Educar em Revista, Curitiba, n. 42, p. 141-162, dez. 2011.

CUNHA, Manuela Carneiro da (Org.). Os direitos do índio: ensaios e documentos. São Paulo: Editora Brasiliense, 1987.

. História dos índios no Brasil. São Paulo: Companhia das Letras; Secretaria Municipal de Cultura; FAPESP, 1992.

DI PIERRO, Maria Clara. A educação de jovens e adultos no Plano Nacional de Educação: avaliação, desafios e perspectivas. Educação \& Sociedade, Campinas - SP, v. 31, n. 112, p. 939-959, set. 2010.

FARAGE, Nádia. As muralhas dos sertões: os povos indígenas no Rio Branco e a colonização. Rio de Janeiro: Paz e Terra; ANPOCS, 1991.

FERREIRA, Marieta de Moraes. Notas sobre a institucionalização dos cursos universitários de História no Rio de Janeiro. In: SALGADO, Manoel (Org). Estudos sobre a escrita da história. Rio de Janeiro: 7 Letras, 2006. p. 145-151. 
GERALDES, Mary Ângela; ROGGERO, Rosemary. Educação e diversidade: demandas do capitalismo contemporâneo. Educação \& Sociedade, Campinas-SP, v. 32, n. 115, p. 471-487, abr./jun. 2011.

GRUPIONI, Luís Donisete Benzi (Org.). Índios no Brasil. Brasília: Ministério da Educação e do Desporto, 1992.

HADDAD, Sérgio; DI PIERRO, Maria Clara. Aprendizagem de jovens e adultos: avaliação da década da educação para todos. São Paulo em Perspectiva, São Paulo, v. 14, n. 1, p. 29-40, mar. 2000.

HORTA, José Silvério. O Hino. O sermão e a ordem do dia: a educação no Brasil (1930-1945). Rio de Janeiro: Ed. UFRJ, 1994.

KNAUSS, Paulo. O desafio da ciência: modelos científicos no ensino de história. Cadernos Cedes, Campinas-SP, v. 25, n. 67, p. 279-295, set./dez. 2005.

KOSELLECK, Reinhart. Futures past. Massachusetts and London: MIT Press Cambridge, 1985, p. 21-38.

MONTEIRO, Ana Maria F. C. Professores: entre saberes e práticas. Educação \& Sociedade, Campinas - SP, v. 22, n. 74, p. 121-142, abr. 2001.

MONTEIRO, John Manuel et al. Índios no estado de São Paulo: resistência e transfiguração. São Paulo: Yancatu Editora \& Comissão Pró-Índio de São Paulo, 1984.

MULLER, Tânia; COELHO, Wilma de Nazaré Baía. A lei n. 10.639/03 e a formação de professores: trajetórias e perspectivas. Revistas da Associação Brasileira de pesquisadores (as) Negros (as) (ABPN), Rio de Janeiro, v. 5, p. 29-54, jan./jun. 2013.

PEREIRA, Graziela Raupp; BAHIA, Alexandre Gustavo Melo Franco. Direito fundamental à educação, diversidade e homofobia na escola: desafios à construção de um ambiente de aprendizado livre, plural e democrático. Educar em Revista, Curitiba, n. 39, p. 51-71, jan./abr. 2011.

RUMMERT, Sonia Maria; VENTURA, Jaqueline Pereira. Políticas públicas para educação de jovens e adultos no Brasil: a permanente (re)construção da subalternidade - considerações sobre os Programas Brasil Alfabetizado e Fazendo Escola. Educar em Revista, Curitiba, n. 29, p. 29-45, jan./jun. 2007.

RÜSEN, Jörn. Como dar sentido ao passado: questões relevantes de meta-história. Revista História da Historiografia, Ouro Preto, n. 2, p. 163-209, mar. 2009.

RÜSEN, Jörn. Razão histórica: teoria da história - fundamentos da ciência histórica. Brasília: Editora da UnB, 2001.

SCHWARTZ, Stuart B. Escravos, roceiros e rebeldes. Bauru: Edusc, 2001.

VADEMARIN, Vera V. O discurso pedagógico como forma de transmissão do conhecimento. Cadernos Cedes, Campinas - SP, v. 19, n. 44, p. 73-84, abril. 1998. 